\title{
Modulation of thalamocortical relay by basal ganglia in Parkinson's disease and dystonia
}

\author{
Yixin Guo ${ }^{1}$, Choongseok Park², Min Rong ${ }^{1}$, Robert M Worth ${ }^{3}$, Leonid L Rubchinsky ${ }^{2,4^{*}}$ \\ From Twentieth Annual Computational Neuroscience Meeting: CNS*2011 \\ Stockholm, Sweden. 23-28 July 2011
}

Two major neurological disorders - Parkinson's disease and dystonia - are believed to involve pathology in the activity of the basal ganglia, a subcortical brain structure, whose output nuclei (internal Globus Pallidus, GPi) projects to thalamus and modulates thalamocortical relay. While these disorders may ultimately involve different network and cellular pathologies, some pathological physiology may be shared between them because surgical treatment of both conditions includes surgical lesion or electrical stimulation to GPi (pallidotomy and GPi DBS). This work compares the thalamocortical relay responses to inhibitory inputs from internal segment of GPi in Parkinson's disease and in dystonia.

Experimental data suggest that both conditions are marked by stronger oscillatory activity. In dystonia this activity becomes pathologically strong in the theta and alpha bands [1,2], while in Parkinson's disease this is the beta-band activity [3]. The activity itself is patterned in time [4], complicating the computational study of its role. To compare the modulation of thalamocortical relay, we use experimental data recorded from GPi of human subjects with Parkinson's disease or dystonia and study the difference of the quality of thalamocortical relay in these conditions following the computational setup, presented earlier in [5].

The results of the study of the "hybrid" system (computational model of TC cell modulated by experimental data) reveal a substantial similarity in the properties of relay in Parkinson's disease and in dystonia. TC relay fidelity is substantially impaired due to the pathological pattern of GPi signals in both conditions. The results

\footnotetext{
* Correspondence: leo@math.iupui.edu

${ }^{2}$ Department of Mathematical Sciences and Center for Mathematical Biosciences, Indiana University Purdue University Indianapolis, Indianapolis, IN 46202, USA

Full list of author information is available at the end of the article
}

are robust with respect to variations of the model details and the types of incoming excitatory synaptic input.

The results suggest that even though the rhythmicity in Parkinson's disease and dystonia are confined to different frequency bands, their effect on the dynamics of downstream circuits is similar. Thus given the differences in dystonic and parkinsonian symptoms these results suggest the existence of mechanisms beyond pathological rhythmicity and thalamocortical relay in at least in one of the conditions. On the other hand, overlap in some motor deficits of dystonia and Parkinson's disease may be attributed to the existence of similar pathological rhythmicities and the resulting deficiencies of thalamic relay.

\section{Acknowledgements \\ This study was supported by NIH grant R01NS067200 (NSF/NIH CRCNS program) and Antelo Devereux Award from Drexel University.}

\section{Author details}

'Department of Mathematics, Drexel University, Philadelphia, PA, 19104, USA. ${ }^{2}$ Department of Mathematical Sciences and Center for Mathematical Biosciences, Indiana University Purdue University Indianapolis, Indianapolis, IN 46202, USA. ${ }^{3}$ Department of Neurological Surgery, Indiana University School of Medicine, Indianapolis, IN 46202, USA. ${ }^{4}$ Stark Neurosciences Research Institute, Indiana University School of Medicine, Indianapolis, IN 46202, USA.

Published: 18 July 2011

\section{References}

1. Hammond C, Bergman H, Brown P: Pathological synchronization in Parkinson's disease: networks, models and treatments. Trends Neurosci 2007, 30:357-364.

2. Silberstein P, Kühn AA, Kupsch A, Trottenberg T, Krauss JK, Wöhrle JC, Mazzone P, Insola A, Di Lazzaro V, Oliviero A, Aziz T, Brown P: Patterning of globus pallidus local field potentials differs between Parkinson's disease and dystonia. Brain 2003, 126:2597-2608.

3. Starr PA, Rau GM, Davis V, Marks WJ Jr, Ostrem JL, Simmons D, Lindsey N, Turner RS: Spontaneous pallidal neuronal activity in human dystonia: comparison with Parkinson's disease and normal macaque. J Neurophysiol 2005, 93:3165-3176.

4. Park C, Worth RM, Rubchinsky LL: Fine temporal structure of beta oscillations synchronization in subthalamic nucleus in Parkinson's disease. J Neurophysiol 2010, 103:2707-2716.

\section{Biomed Central}


5. Guo Y, Rubin JE, McIntyre CC, Vitek JL, Terman D: Thalamocortical relay fidelity varies across subthalamic nucleus deep brain stimulation protocols in a data-driven computational model. J Neurophysiol 2008, 99:1477-1492.

doi:10.1186/1471-2202-12-S1-P275

Cite this article as: Guo et al: Modulation of thalamocortical relay by basal ganglia in Parkinson's disease and dystonia. BMC Neuroscience 2011 12(Suppl 1):P275.

Submit your next manuscript to BioMed Central and take full advantage of:

- Convenient online submission

- Thorough peer review

- No space constraints or color figure charges

- Immediate publication on acceptance

- Inclusion in PubMed, CAS, Scopus and Google Scholar

- Research which is freely available for redistribution

Submit your manuscript at www.biomedcentral.com/submit 